\section{Modification of the haemodynamic responses to induction of anaesthesia and tracheal intubation with alfentanil, esmolol and their combination}

The purpose of this double-blind randomized work was to study the effect of alfentanil and esmolol and their half-dose combination on the increases of heart rate and arterial pressure and on the prolongation of the QTC interval of the ECG occurring during anaesthetic induction. Sixty ASA class I-II patients with mean age ranging from 26 to $32 \mathrm{yr}$ among the groups. Patients were allocated to one of four equal groups to receive saline, esmolol $2 \mathrm{mg} \cdot \mathrm{kg}^{-1}$, alfentanil $0.03 \mathrm{mg} \cdot \mathrm{kg}^{-1}$ and alfentanil $0.015 \mathrm{mg} \cdot \mathrm{kg}^{-1}+$ esmolol $1 \mathrm{mg} \cdot \mathrm{kg}^{-1}$. Anaesthesia was induced with thiopentone. Succinylcholine was used to facilitate tracheal intubation. Haemodynamic variables were measured non-invasively and the QTc interval with the aid of a microcomputer. Comparisons between the groups were performed using two-way analysis of variance with repeated measures. Both alfentanil and alfentanil-esmolol prevented the increase of heart rate and arterial pressure caused by intubation whereas esmolol prevented only the increase of the heart rate. None of the treatments prevented prolongation of the QTc interval after intubation and only alfentanil prevented that after

\section{Key words}

ANAESTHESIA: induction;

ANALGESICS: alfentanil;

INTUBATION: complications;

SYMPATHETIC NERVOUS SYSTEM: beta adrenergic antagonists, esmolol.

From the Department of Anaesthesia, Otolaryngological Hospital, Helsinki University Central Hospital, Helsinki, Finland*, Ragnar Granit Institute, Tampere University of Technology, Tampere, Finland $\dagger$ and Department of Public Health, Helsinki University, Helsinki, Finlandł.

Address correspondence to: Dr. R. Korpinen, Department of Anaesthesia, Otolaryngological Hospital, Haartmaninkatu, 4

E, 00290 Helsinki, Finland.

Accepted for publication 2nd December, 1994.
R. Korpinen $M D,{ }^{*}$ L. Saarnivaara MD, ${ }^{*}$

K. Siren PhD, $\dagger$ S. Sarna PhD $\ddagger$ succinylcholine. The present results suggest that in the prevention of the haemodynamic responses to tracheal intubation, the half-dose combination of alfentanil and esmolol is as effective as alfentanil and superior to esmolol. The combination is preferable to relatively large doses of either drug in circumstances where side effects, such as respiratory depression due to alfentanil or bradycardia due to both drugs should be min. imized.

Ce travail randomisé en double-aveugle avait pour but l'étude des effets de l'association de l'alfentanil avec l'esmolol à demidoses sur l'augmentation de la fréquence cardiaque et de la pression artérielle, et sur la prolongation de lintervalle $Q T_{C}$ de l'ECG pendant linduction de l'anesthésie. Soixante patients ASA I et II dont la moyenne d'âge variait entre 25 et 32 ans ont fait partie de l'étude. Ces patients ont été répartis en quatre groupes pour recevoir respectivement: du soluté physiologique, de l'esmolol $2 \mathrm{mg} \cdot \mathrm{kg}^{-1}$, de lalfentanil $0,03 \mathrm{mg} \cdot \mathrm{kg}^{-1}$, et de l'alfentanil $0,015 \mathrm{mg} \cdot \mathrm{kg}^{-1}+$ esmolol $1 \mathrm{mg} \cdot \mathrm{kg}^{-1}$. L'anesthésie a été induite au thiopentone. La succinylcholine a été utilisée pour l'intubation. Les paramètres hémodynamiques ont été enregistrés par voie non effractive et lintervalle $Q T c$ grâce à un micro-ordinateur. Les comparaisons ont été établies sur des mesures répétées par analyse de variance. L'alfentanil et l'alfentanil + esmolol ont empêché l'augmentation de la fréquence cardiaque et de la pression artérielle causée par lintubation alors que l'esmolol n'a été efficace sur l'augmentation de la fréquence cardiaque. Aucun des traitements n'a été efficace pour la prévention de la prolongation de lintervalle QTC après lintubation et seul l'alfentanil l'a été après la succinylcholine. Ces résultats suggèrent que pour prévenir les effets hémodynamiques de lintubation, une demi-dose d'esmolol avec alfentanil est aussi efficace que l'alfentanil et supérieure à l'esmolol. Cette association est préférable à des doses relativement plus fortes de chacune des drogues dans les circonstances au cours desquelles les effets secondaires comme la dépression respiratoire due à l'alfentanil 
ou la bradycardie due aux deux drogues doivent être réduites au minimum.

It has been shown that alfentanil prevents haemodynamic responses to tracheal intubation. ${ }^{1-3}$ Alfentanil is a potent opioid with a rapid onset and short duration of action. . $^{4-6}$ In addition, the frequency of postoperative nausea and vomiting is less in patients treated with alfentanil than in those treated with another relatively short-acting opioid, fentanyl. ${ }^{34,35}$ On the other hand, it is well known from clinical practice that some operations and procedures, especially those concerning the mouth and upper respiratory tract, e.g., tonsillectomy, hypopharyngoscopy, laryngomicroscopy and bronchoscopy, are of brief duration, but cause considerable haemodynamic stimulation. It is possible to perform many of these procedures on an outpatient basis, if the patients do not suffer from postoperative side effects, of which the most disturbing is nausea and vomiting. Therefore, the short-acting alfentanil is preferable for these procedures to other longeracting opioids. However, in some cases, particularly in outpatient anaesthesia, the action of alfentanil might be too long.

Esmolol is a cardioselective, short-acting beta-blocking agent. Previous studies have established the effectiveness of bolus doses of esmolol in the reduction of haemodynamic responses during anaesthetic induction. ${ }^{7-11}$ However, prevention of the haemodynamic responses to intubation has not been complete. ${ }^{7-11}$

In addition to the haemodynamic responses, we studied the QTc interval of the ECG since it is prolonged during anaesthetic induction, especially after succinylcholine and tracheal intubation. ${ }^{15-18}$ The clinical importance of the prolongation in patients with normal hearts is not known, but ventricular fibrillation, ${ }^{24}$ cardiac arrhythmias ${ }^{25}$ and even death ${ }^{26}$ have occurred during general anaesthesia in patients suffering from a prolonged QT interval syndrome or an acute myocardial infarction. In earlier studies both alfentanil ${ }^{23}$ and beta-blocking agents practolol and metoprolol ${ }^{16}$ attenuated the prolongation of the QTc interval during anaesthetic induction.

The present study was designed to compare the effects of alfentanil $30 \mu \mathrm{g} \cdot \mathrm{kg}^{-1}$ and esmolol $2 \mathrm{mg} \cdot \mathrm{kg}^{-1}$ with those of their half-dose combination on heart rate, arterial pressure and on QTc interval during anaesthetic induction in patients undergoing otolaryngological surgery.

\section{Methods}

The study was carried out in 60 ASA class I or II patients without cardiovascular or respiratory disease or any preoperative medication. The mean age of the patients ranged from 26 to $32 \mathrm{yr}$ among groups. The protocol of the study was approved by the Ethics Committee of the Otolaryngological Hospital.

Patients were premedicated with oxycodone (Oxanest ${ }^{\circledR}$ ) $0.1 \mathrm{mg} \cdot \mathrm{kg}^{-1}$ and atropine (Atropin ${ }^{\circledR}$ ) 0.01 $\mathrm{mg} \cdot \mathrm{kg}^{-1}$ im about $60 \mathrm{~min}$ before anaesthesia. In this double-blind study, the patients were randomly allocated to one of the four groups: esmolol (Breviblock ${ }^{\circledR}$ ) 2 $\mathrm{mg} \cdot \mathrm{kg}^{-1}$ (Esm), alfentanil (Rapifen $\left.{ }^{\circledR}\right) 30 \mu \mathrm{g} \cdot \mathrm{kg}^{-1}$ (Alf), alfentanil $15 \mu \mathrm{g} \cdot \mathrm{kg}^{-1}+$ esmolol $1 \mathrm{mg} \cdot \mathrm{kg}^{-1}$ (Alf+Esm) or saline (Sal). The doses of alfentanil and esmolol were chosen on the basis of our preliminary pilot studies as well as earlier studies. ${ }^{1-3,7-11}$

Either esmolol (Esm) or alfentanil (Alf) was drawn into two $10 \mathrm{ml}$ syringes (number 1 and number 2), containing half of the calculated dose of the drug in each syringe. In the case of the combination of esmolol and alfentanil (Alf + Esm), esmolol was drawn into a $10 \mathrm{ml}$ syringe, number 1 , and alfentanil into another $10 \mathrm{ml}$ syringe, number 2. Thereafter saline was drawn to make up a volume of $10 \mathrm{ml}$ in each syringe. In the Sal group the patients received $20 \mathrm{ml}$ saline in two $10 \mathrm{ml}$ syringes (number 1 and number 2).

At zero time, the study drugs (first syringe number 1 and then number 2) were injected over $45 \mathrm{sec}$. Thiopentone $5 \mathrm{mg} \cdot \mathrm{kg}^{-1}$ was started $15 \mathrm{sec}$ later and was injected over $45 \mathrm{sec}$. Succinylcholine $1.5 \mathrm{mg} \cdot \mathrm{kg}^{-1}$ was injected $15 \mathrm{sec}$ later. Tracheal intubation was performed one minute after succinylcholine. During induction, the patients breathed $100 \% \mathrm{O}_{2}$ spontaneously until injection of thiopentone. Thereafter, their lungs were ventilated until intubation. The end-tidal $\mathrm{CO}_{2} \%$ (Datex capnograph) varied between 5-6 vol. \% in all groups immediately after intubation.

Systolic and diastolic arterial pressure were automatically measured and registered with a Nippon Colin BP1001 sphygmomanometer immediately before the injection of the study drugs, at one and two minute as well as about $15 \mathrm{sec}$ and three minutes after intubation. The QT, QRS and ST intervals of the ECG (lead II) were measured by a signal processing method of the ECG at the same time as arterial pressure and, in addition, $30 \mathrm{sec}$ after succinylcholine (Figure 1).

The signal processing method was based on an IBM PC/XT-compatible microcomputer. The other parts of the system were an A/D converter, a board including an amplifier with a gain of three and a low pass filter with a cut-off frequency of $100 \mathrm{~Hz}$ for signal antialiasing. The total system was made compact by inserting all external electronics required into the PC's expansion slots. In each case, the mean QT, QRS and ST intervals of successive beats occurring over ten seconds were determined. After analysis, the results were displayed on the screen and saved on a floppy disk for later examination. 


\begin{tabular}{|c|c|c|c|c|c|c|c|c|}
\hline$x$ & & (1 min) & $x$ & (i min) & $x$ & (1 $\stackrel{(\mathrm{X})}{\mathrm{min})}$ & $x$ & $(3 \mathrm{~min})$ \\
\hline $100 \% 0_{1}$ & $\begin{array}{c}\uparrow \\
\text { Study drug }\end{array}$ & & $\begin{array}{c}\uparrow \\
\text { Thiopentone }\end{array}$ & & $\begin{array}{c}\uparrow \\
\text { Succinyleholir }\end{array}$ & & $\begin{array}{c}\uparrow \\
\text { Intubation }\end{array}$ & $\begin{array}{c}\uparrow \\
\text { After intubation }\end{array}$ \\
\hline
\end{tabular}

FIGURE 1 Time line of events and data collection points. $X=$ measurement of heart rate, systolic and diastolic pressure and ECG parameters, $(X)=$ measurements only ECG parameters.

The cycle could be repeated either according to a programmed timetable or manually by the user. Bazett's formula $(Q T / \sqrt{R-R})^{12}$ was used for the correction of the QT interval for heart rate. The ECG, lead II, was displayed continuously on an oscilloscope and recorded continuously at every study period.

Two-way analysis of variance with repeated measures was used for comparisons among groups. ${ }^{13}$ Paired Student's $t$ test was used for the comparisons within the groups. The $P$ values were adjusted using the Bonferroni multiple testing correction. A $P$ value $<0.05$ was regarded as statistically significant.

\section{Results}

\section{Heart rate}

The mean control values of the groups were comparable. Both the drugs $(P<0.01)$ and the time $(P<0.0001)$ as well as their interaction $(P<0.0001)$ markedly affected the results (Figure 2). When the groups were compared pairwise, both the Alf $(P<0.01)$ and Alf+Esm groups $(P<0.001)$ differed from the Sal group. Other pairwise comparisons were not significant.

No changes occurred in the Esm, Alf or Alf+Esm groups compared with the corresponding control values. Both immediately and three minutes after intubation, the heart rate increased in the Sal group compared with the corresponding control value (Figure 2).

\section{Systolic arterial pressure}

The mean control values of the groups were comparable. Both the drugs $(P<0.01)$ and the time $(P<0.0001)$ as well as their interaction $(P<0.0001)$ markedly affected the results (Figure 3 ). When the groups were compared pairwise, both the Alf $(P<0.01)$ and the Alf + Esm groups $(P<0.01)$ differed from the Sal group. Other pairwise comparisons were not significant.

After thiopentone, systolic arterial pressure decreased in all groups whereas after intubation, it increased in the Sal and the Esm groups compared with the corresponding control values. Three minutes after intubation, systolic arterial pressure was decreased in the Alf and Alf+Esm groups compared with the corresponding control values (Figure 3).

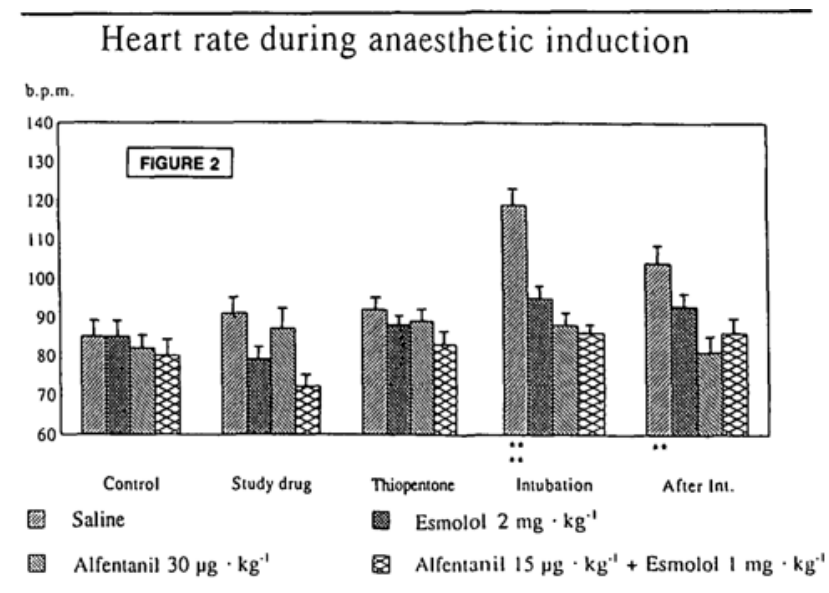

Systolic arterial pressure during anaesthetic induction $\mathrm{mmHg}$

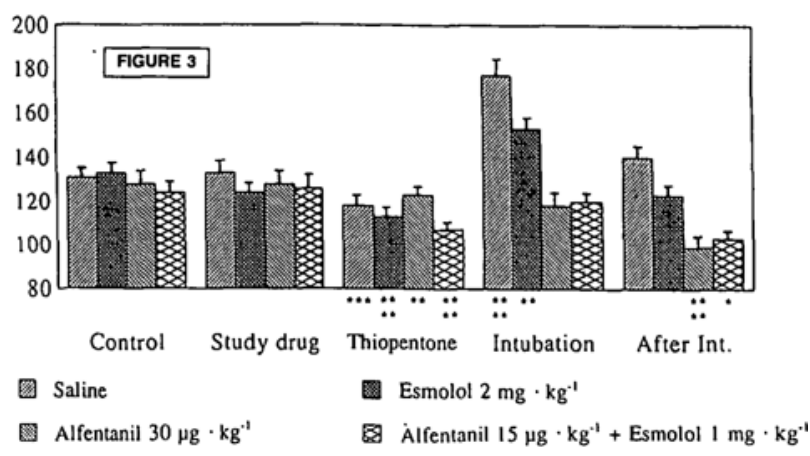

Diastolic arterial pressure during anaesthetic induction $\mathrm{mmHg}$

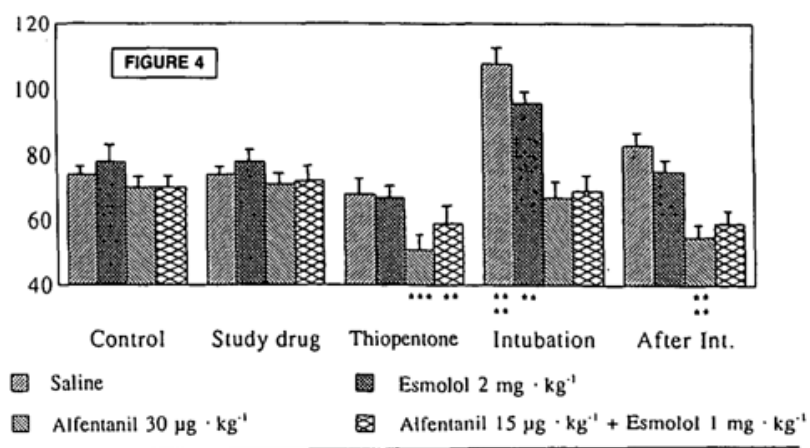

FIGURES 2-4 Heart rate, systolic and diastolic arterial pressure in the four anaesthetic groups (means \pm SEM). Control $=$ just before induction. Study drug $=15 \mathrm{sec}$ after injection of study drug.

Thiopentone $=15 \mathrm{sec}$ after injection of thiopentone. Intubation $=15$ sec after intubation. After int. $=$ three minutes after intubation. Fifteen patients in each group. ${ }^{*} P<0.05,{ }^{* *} P<0.01,{ }^{* * *} P<0.001,{ }^{* * * *} P$ $<0.0001$ compared with the corresponding control value. Comparisons between the groups using two-way ANOVA with repeated measure. Drugeffect for heart rate, systolic and diastolic pressure: $P<0.01, P<0.01, P<0.0001$, respectively, time- and interaction-effects: for all variables $P<0.0001$.

\section{Diastolic arterial pressure}

The mean control values of the groups were comparable. 
Both the drugs $(P<0.0001)$ and the time $(P<0.0001)$ as well as their interaction $(P<0.0001)$ markedly affected the results (Figure 4). When the groups were compared pairwise both the Alf $(P<0.0001)$ and the Alf + Esm groups $(P<0.01)$ differed from the Sal group as well as the Alf $(P<0.001)$ and the Alf+Esm groups $(P<0.01)$ from the Esm group.

After thiopentone, diastolic arterial pressure decreased in the Alf and the Alf + Esm groups whereas after intubation, it increased in the Sal and Esm groups compared with the corresponding control values. Three minutes after intubation, diastolic arterial pressure decreased in the Alf group compared with the corresponding control value (Figure 4).

\section{$Q T c, S T$ and $Q R S$ interval of the ECG}

The mean control values of these variables were comparable in the groups and the mean QTc intervals were in the normal range ( $<440 \mathrm{msec}$ according to the Bazett's formula). Both the time $(P<0.0001)$ and its interaction with the drugs $(P<0.0001)$, but not the drugs alone, affected the QTc interval (Figure 5). When the groups were compared pairwise, the Alf + Esm group differed from the Sal group $(P<0.05)$. Other pairwise comparisons were not different.

After the study drug, the QTc interval decreased in the Esm and Alf+Esm groups whereas, after succinylcholine, it increased in the Sal, Esm and Alf+Esm groups compared with the corresponding control values. After intubation, the QTc interval increased in all groups and it remained increased in the Esm and Alf+Esm groups up to three minutes after intubation when compared with the corresponding control values (Figure 5).

The mean control QRS values in the groups were comparable. In the QRS interval, there were no changes within or between the groups (Table I).

Both the time $(P<0.0001)$ and its interaction $(P<$ 0.0001 ) with the drugs, but not the drugs alone, affected the ST interval. None of the pairwise comparisons were significant.

After intubation, the ST interval increased in the Alf +Esm group, whereas three minutes after intubation it decreased in the Sal group compared with the corresponding control values (Table II).

No cardiac arrhythmias were noticed in any of the groups.

\section{Discussion}

\section{Heart rate and arterial pressure}

In the control of the heart rate and arterial pressure after tracheal intubation, alfentanil $30 \mu \mathrm{g} \cdot \mathrm{kg}^{-1}$ was a satisfactory treatment, whereas esmolol $2 \mathrm{mg} \cdot \mathrm{kg}^{-1}$ prevented
QTc interval of ECG during anaesthetic induction

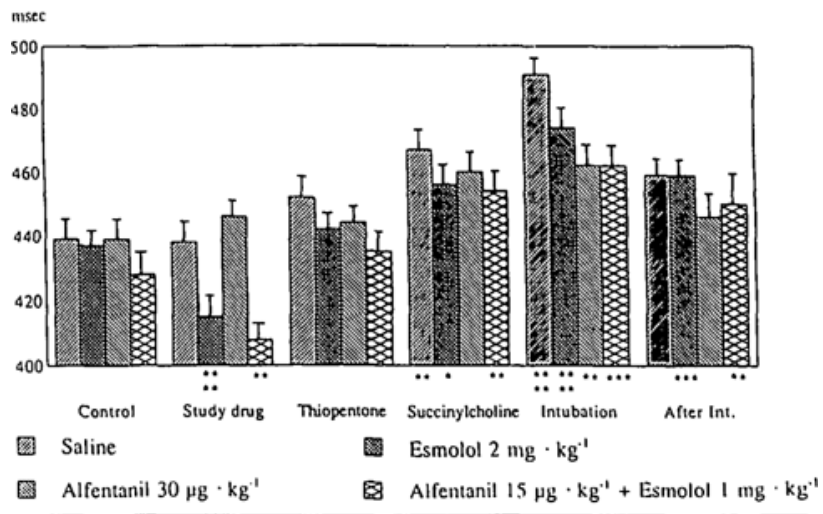

FIGURE 5 QTc intervals in the four anaesthetic groups (means \pm SEM). Control = just before induction, study drug $=15 \mathrm{sec}$ after injection of the study drug, thiopentone $=15 \mathrm{sec}$ after injection of thiopentone, succinylcholine $=30 \mathrm{sec}$ after injection of succinylcholine, intubation $=15 \mathrm{sec}$ after intubation. After int. $=$ three minutes after intubation. Fifteen patients in each group. ${ }^{*} P<0.05,{ }^{* *} P<0.01$, ${ }^{* * *} P<0.001,{ }^{* * * *} P<0.0001$ compared with the corresponding control value. Comparison using two-way ANOVA with repeated measure. Drugeffect $P>0.05$, time-effect $P<0.0001$, interactioneffect $P<0.0001$.

TABLE I QRS interval during anaesthetic induction

\begin{tabular}{lllll}
\hline & \multicolumn{3}{l}{ QRS interval (msec) } \\
\cline { 2 - 3 } $\begin{array}{l}\text { Stage of } \\
\text { induction }\end{array}$ & \multicolumn{2}{l}{ Study drug $\mathrm{mg} \cdot \mathrm{kg}^{-1}$} \\
\cline { 2 - 5 } & Sal & Esm 2 & Alf 0.03 & Alf $0.015+$ Esm l \\
\hline Control & $89+3.1$ & $91+2.6$ & $91+3.1$ & $92+3.2$ \\
Study drug & $89+2.9$ & $92+2.7$ & $91+2.9$ & $92+2.8$ \\
Thiopentone & $89+3.2$ & $91+2.8$ & $90+3.1$ & $93+3.0$ \\
Succinylcholine & $89+3.6$ & $92+2.7$ & $91+2.9$ & $93+3.0$ \\
Intubation & $90+3.5$ & $89+2.3$ & $91+3.4$ & $92+2.9$ \\
After int. & $88+2.3$ & $92+2.6$ & $90+2.9$ & $91+2.6$ \\
\hline
\end{tabular}

Mean + SEM. $N=15$. Sal $=$ saline, Esm $=$ esmolol, Alf = alfentanil Control $=$ prior to induction, study drug $=15 \mathrm{sec}$ after injection of study drug, thiopentone $=15 \mathrm{sec}$ after injection of thiopentone, succinylcholine $=30 \mathrm{sec}$ after injection of succinylcholine, intubation $=$ $15 \mathrm{sec}$ after intubation, After int. = three minutes after intubation.

the increase of the heart rate but not that of arterial pressure. These results are comparable with those obtained in previous studies. ${ }^{1-3,7-11}$ The present as well as earlier results suggest that alfentanil is useful in the prevention of cardiovascular responses to intubation in circumstances where operations are long enough to avoid postoperative respiratory depression due to alfentanil. However, esmolol $2 \mathrm{mg} \cdot \mathrm{kg}^{-1}$ alone was not satisfactory.

After intubation, both 15 and $30 \mu \mathrm{g} \cdot \mathrm{kg}^{-1}$ alfentanil prevented the increase of arterial pressure, but only 30 $\mu \mathrm{g} \cdot \mathrm{kg}^{-1}$ prevented that of the heart rate. 'In the present study, the combination of alfentanil $15 \mu \mathrm{g} \cdot \mathrm{kg}^{-1}$ and es- 
TABLE II ST interval during anaesthetic induction

\begin{tabular}{lllll}
\hline & \multicolumn{3}{l}{ ST interval (msec) } \\
\cline { 2 - 3 } $\begin{array}{l}\text { Stage of } \\
\text { induction }\end{array}$ & \multicolumn{2}{l}{ Studydrug $\mathrm{mg} \cdot \mathrm{kg}^{-1}$} & & \\
\cline { 2 - 3 } & Sal & Esm 2 & Alf 0.03 & Alf $0.015+$ Esm I \\
\hline Control & $272+6.8$ & $274+8.0$ & $281+8.0$ & $282+8.6$ \\
Study drug & $273+7.4$ & $266+7.6$ & $274+9.8$ & $272+8.7$ \\
Thiopentone & $275+6.0$ & $276+8.1$ & $277+8.0$ & $281+7.6$ \\
Succinylcholine & $275+5.4$ & $282+7.6$ & $286+8.1$ & $285+7.6$ \\
Intubation & $261+5.8$ & $285+6.8$ & $292+8.9$ & $291+7.8^{*}$ \\
After int. & $247+5.6^{*} 269+6.0$ & $286+9.6$ & $280+7.4$ \\
\hline
\end{tabular}

Comparisons using two-way ANOVA with repeated measure (ST): drug-effect $P<0.05$, time-effect $P>0.0001$, interaction-effect $P<$ 0.0001 . ${ }^{*} P<0.05$ compared with the corresponding control values.

molol $1 \mathrm{mg} \cdot \mathrm{kg}^{-1}$ prevented the increase of both the arterial pressure and heart rate after intubation. Miller $e t$ $a l^{7}$ reported effective control of both heart rate and arterial pressure by using the combination of esmolol 100 $\mathrm{mg}$ and fentanyl 2-3 $\mu \mathrm{g} \cdot \mathrm{kg}^{-1}$. Furthermore, similar to the present results, Chung et al. ${ }^{14}$ reported that the combination of fentanyl $2 \mu \mathrm{g} \cdot \mathrm{kg}^{-1}$ and esmolol $2 \mathrm{mg} \cdot \mathrm{kg}^{-1}$ provided an alternative to a higher dose of fentanyl (5 $\mu \mathrm{g} \cdot \mathrm{kg}^{-1}$ ) for preventing the haemodynamic responses to intubation.

The main message of the present study is that it is possible to reduce the dose and also the side effects of alfentanil and esmolol by using their half-dose combination. Alfentanil is a short-acting opioid, but respiratory depression due to alfentanil correlated with dose. ${ }^{34}$ Therefore, the dose of alfentanil should be reduced in outpatient anaesthesia or in very short operations with minimal postoperative pain, e.g., microlaryngoscopy and oesophagoscopy. The pharmacodynamic behaviour of alfentanil is similar in both young and elderly patients, ${ }^{31}$ but elderly patients tolerate alfentanil less well. ${ }^{31,32}$ Therefore, contrary to the present patients who were aged $<50 \mathrm{yr}$ and without cardiovascular diseases, the lower dose of alfentanil might be preferable for anaesthesia in elderly patients. Furthermore, both alfentanil and esmolol cause dose-dependent bradycardia. Doses $>20 \mu \mathrm{g} \cdot \mathrm{kg}^{-1}$ alfentanil in combination with succinylcholine caused severe bradycardia and even asystole. ${ }^{33}$ Esmolol, 2.5-3 $\mathrm{mg} \cdot \mathrm{kg}^{-1}$, reduced the cardiac index and ejection fraction in healthy patients. ${ }^{30}$ On this basis, reduction of the dose of esmolol seems to be advantageous. However, it should be remembered that the present results are only applicable to patients receiving anticholinergic premedication.

\section{QTc interval}

In the present study, the QTc interval decreased in both the esmolol and alfentanil+esmolol groups compared with corresponding control values. This differs from the results obtained by Greenspan and others, ${ }^{19}$ who observed no changes in the QTc interval after esmolol infusion. One reason might be the different dosing methods. Furthermore, practolol and metoprolol did not affect the QTc interval. ${ }^{16}$ However, in one study, atenolol induced a marked and constant reduction of the QTc interval ${ }^{20}$ whereas acebutolol ${ }^{20}$ and an unselective beta-receptor blocker sotalol ${ }^{21}$ prolonged the QTC interval. These results show that the effect of beta-blockers on the QTc interval is inconsistent.

The present result, that the QTc interval in the saline group was prolonged after succinylcholine and intubation, confirms earlier results. ${ }^{15-18}$ In the present study esmolol did not prevent prolongation of the QTc interval after succinylcholine and intubation, compared either with the other groups or with the control values within the group. However, practolol $100 \mu \mathrm{g} \cdot \mathrm{kg}^{-1}$ and metoprolol $20-40$ $\mu \mathrm{g} \cdot \mathrm{kg}^{-1}$ prevented, in a dose-dependent fashion, the prolongation of the QTc interval after succinylcholine but not that after intubation. ${ }^{16}$

In the present study, neither alfentanil nor the halfdose combination of alfentanil and esmolol prevented the prolongation of the QTc interval after intubation. This differs from the results obtained in midazolampremedicated children ${ }^{22}$ and in diazepam-meperidinepremedicated adults ${ }^{23}$ in whom alfentanil prevented the increase of the QTc interval after both succinylcholine and intubation. However, premedication, the doses of alfentanil and the ages of the patients differed from the present study.

The patients in the present study did not suffer from heart diseases. The importance of prolongation of the QTc interval for the normal heart is controversial. In some studies, there has been a correlation between the prolongation of the QTc interval and the occurrence of cardiac arrhythmias, especially ventricular ectopic beats after laryngoscopy and intubation. ${ }^{15,18,22}$ On the other hand, some investigators have found no correlation between the prolongation of the QTc interval and cardiac arrhythmias. ${ }^{16,17,27}$ Further, d-tubocurarine prevented the prolongation of the QTc interval during anaesthetic induction and decreased the incidence of cardiac arrhythmias. ${ }^{27}$ In children, the QTc interval was prolonged during enflurane induction ${ }^{28}$ but remained unchanged during induction with halothane ${ }^{29}$ without cardiac arrhythmias in either of the studies. On this basis, prolongation of the QTc interval often seems to be related to cardiac arrhythmias, but their appearance might also be affected by the antiarrhythmic properties of the drugs. This is supported by the observation that, despite the prolongation of the QTc interval in the presence of esmolol, 
there were no cardiac arrhythmias. This may have been due to antiarrhythmic properties of esmolol. .0,36

It is concluded that the half-dose combination of alfentanil and esmolol prevented the haemodynamic responses to intubation better than esmolol $2 \mathrm{mg} \cdot \mathrm{kg}^{-1}$ and the prevention was comparable with that by alfentanil $30 \mu \mathrm{g} \cdot \mathrm{kg}^{-1}$. None of the treatments prevented prolongation of the QTc interval during anaesthetic induction. It is possible to control haemodynamic responses during anaesthetic induction by reducing the dosage and also side effects of alfentanil and esmolol by using them together.

\section{Acknowledgements}

We are very grateful to Markku Simola MD for making possible the use of his statistical programs. We also wish to thank all nurse anaesthetists for their excellent assistance during the study. The study was supported by the Päivikki and Sakari Sohlberg Foundation, Helsinki, Finland.

\section{References}

1 Black TE, Kay B, Healy TEJ. Reducing the haemodynamic responses to laryngoscopy and intubation. A comparison of alfentanil with fentanyl. Anaesthesia 1984; 39: 883-7.

2 Saarnivaara $L$, Klemola $U$-M. Alfentanil as an adjuvant of balanced anaesthesia for tonsillectomy in adults. Acta Anaesthesiol Scand 1987; 31: 1-6.

3 Martineau RJ, Tousignant CP, Miller DR, Hull KA. Alfentanil controls the haemodynamic response during rapid-sequence induction of anaesthesia. Can $\mathrm{J}$ Anaesth 1990; 37: 755-61.

4 Scott JC, Ponganis KV, Stanski DR. EEG quantitation of narcotic effect: the comparative pharmacodynamics of fentanyl and alfentanil. Anesthesiology 1985; 62: 234-41.

5 Bovill JG, Sebel PS, Blackburn CL, Heykants J. The pharmacokinetics of alfentanil (R30209): a new opioid analgesic. Anesthesiology 1982; 57: 439-43.

6 Camu F, Gepts E, Rucquoi M, Heykants J. Pharmacokinetics of alfentanil in man. Anesth Analg 1982; 61: 657-61.

7 Miller DR, Martineau RJ, Wynands JE, Hill J. Bolus administration of esmolol for controlling the haemodynamic response to tracheal intubation: the Canadian multicentre trial. Can J Anaesth 1991; 38: 849-58.

8 Sheppard S, Eagle CJ, Strunin L. A bolus dose of esmolol attenuates tachycardia and hypertension after tracheal intubation. Can J Anaesth 1990; 37: 202-5.

9 Liu PL, Gatt S, Gugino LD, Mallampati SR, Covino BG. Esmolol for control of increases in heart rate and blood pressure during tracheal intubation after thiopentone and succinylcholine. Can Anaesth Soc J 1986; 33: 556-62.
10 Oxorn D, Knox JWD, Hill J. Bolus doses of esmolol for the prevention of perioperative hypertension and tachycardia. Can J Anaesth 1990; 37: 206-9.

11 Knox JWD, Oxorn $D C$. Esmolol is efficient in controlling post-intubation tachycardia and hypertension. Can J Anaesth 1989; 36: S165-6.

12 Bazett HC. An analyis of the time relations of the electrocardiogram. Heart 1920; 7: 353-70.

13 Statistica. StatSoft 1991. Tulsa.

14 Chung KS, Sinatra RS, Halevy JD, Paige D, Silverman $D G$. A comparison of fentanyl, esmolol, and their combination for blunting the haemodynamic responses during rapid-sequence induction. Can J Anaesth 1992; 39: 774-9.

15 Saarnivaara $L$, Lindgren $L$. Prolongation of the QT interval during induction of anaesthesia. Acta Anaesthesiol Scand 1983; 27: 126-30.

16 Saarnivaara $L$, Lindgren $L$, Hynynen $M$. Effects of practolol and metoprolol on QT interval, heart rate and arterial pressure during induction of anaesthesia. Acta Anaesthesiol Scand 1984; 28: 644-8.

17 Saarnivaara $L$, Klemola $U-M$, Lindgen $L$, Rautiainen $P$, Suvanto A. QT interval of the ECG, heart rate and arterial pressure using propofol, methohexital or midazolam for induction of anaesthesia. Acta Anaesthesiol Scand 1990; 34: 276-81.

18 Saarnivaara L, Hiller A, Oikkonen $M$. QT interval, heart rate and arterial pressure using propofol, thiopentone or methohexital for induction of anaesthesia in children. Acta Anaesthesiol Scand 1993; 37: 419-23.

19 Greenspan AM, Spielman SR, Horowitz LN, Senior $S$ Steck J, Laddu A. Electrophysiology of esmolol. Am J Cardiol 1985; 56: 19F-26F.

20 Pala AM, Ricciardelli D, Sanna A, Vinattieri $M A$. The effect of beta blockers on the QT interval: possible role of mechanisms other than beta block (Italian). Minerva Med 1989; 80: 1283-7.

21 Dumoulin P, Weissenburger J, Poirier JM, et al. Electrophysiological effects of intravenous sotalol. Relation with plasma levels (French). Arch Mal Coeur Vaiss 1985; 78: $562-8$.

22 Lindgren L, Rautiainen P, Klemola U-M, Saarnivaara $L$. Haemodynamic responses and prolongation of QT interval of ECG after suxamethonium-facilitated intubation during anaesthetic induction in children: a dose-related attenuation by alfentanil. Acta Anaesthesiol Scand 1991; 35: 355-8.

23 Scheinin B, Scheinin M, Vuorinen J, Lindgren $L$. Alfentanil obtunds the cardiovascular and sympathoadrenal responses to suxamethonium-facilitated laryngoscopy and intubation. Br J Anaesth 1989; 62: 385-92.

24 Forbes $R B$, Morton $G H$. Ventricular fibrillation in a patient with unsuspected mitral valve prolapse and prolonged Q-T interval. Can Anaesth Soc J 1979; 26: 424-7.

25 Medak $R$, Benumof JL. Perioperative management of the 
prolonged Q-T interval syndrome. Br J Anaesth 1983; 55: 361-4.

26 Schwartz PJ, Wolf S. QT interval prolongation as predictor of sudden death in patients with myocardial infarction. Circulation 1978; 57: 1074-7.

27 Saarnivaara $L$, Klemola $U-M$, Lindgren $L$. QT interval of the ECG, heart rate and arterial pressure using five nondepolarizing muscle relaxants for intubation. Acta Anaesthesiol Scand 1988; 32: 623-8.

28 Lindgren $L$, Saarnivaara $L$. Cardiovascular responses to enflurane induction followed by suxamethonium in children. Br J Anaesth 1983; 55: 269-73.

29 Lindgren $L$, Saarnivaara $L$. Cardiovascular responses to tracheal intubation in small children. Br J Anaesth 1985; 57: 1183-7.

30 Miller $D$, Martineau $R$. Esmolol for control of haemodynamic responses during anaesthetic induction. Can $\mathbf{J}$ Anaesth 1989; 36: S164-5.

31 Lemmens H, Bovill J, Hennis PJ, Burm AGL. Age has no effect on the pharmacodynamics of alfentanil. Anesth Analg 1988; 67: 956-60.

32 Kirby IJ, Northwood D, Dodson ME. Modification by alfentanil of the haemodynamic response to tracheal intubation in elderly patients. Br J Anaesth 1988; 60: 384-7.

33 Reid $C$, Crosby $E$, Reid $D$. Sinus arrest following administration of alfentanil (Letter). Can J Anaesth 1991; 38: 540-1.

34 Scamman $F$, Ghoneim $M$, Kortila $K$. Ventilatory and mental effects of alfentanil and fentanyl. Acta Anaesthesiol Scand 1984; 28: 63-7.

35 Patrick M, Eager BM, Toft DF, Sebel PS. Alfentanilsupplemented anaesthesia for short procedures. A doubleblind comparison with fentanyl. Br J Anaesth 1984; 56: 861-6.

36 Dimick I, Lingham $R$, Narang J, Sampson I, Shiang $H$. Esmolol prevents and suppresses arrhythmias during halothane anaesthesia in dogs. Can J Anaesth 1992: 39: 83-6. 